\title{
LARGE PERTURBATIONS OF AMMONIUM AND ORGANIC ACIDS CONTENT IN THE SUMMTT- GREENLAND ICE CORE. FINGERPRINT FROM FOREST FIRES?
}

\author{
M. Legrand and M. De Angelis \\ Laboratoire de Glaciologie et Géophysique de l'Environnement
}

T. Staffelbach, A. Neftel and B. Stauffer

Physical Institut, University of Bern

\begin{abstract}
Biomass burning is influencing the atmospheric chemistry by emitting large amounts of reactive species such as hydrocarbons, organic acids and nitrogen compounds [Andreae et al., 1988]. Polar ice cores provide a unique record of precipitation whose chemistry reflects the atmospheric composition at the time of deposition. The analysis of such ice samples therefore allows an estimate to be made of the concentration of atmospheric impurities in the past During the first season of the deep drill operation (GRIP) at Summit, Central Greenland ( $\left(72^{\circ} 34^{\prime} \mathrm{N}, 37^{\circ} 38^{\prime} \mathrm{W}\right.$ ) continuous ammonium $\left(\mathrm{NH}_{4}{ }^{+}\right)$measurements were performed between 100 and $600 \mathrm{~m}$ depth covering the time period from 330 to 2500 years B.P. The $\mathrm{NH}_{4}{ }^{+}$concentrations show seasonal variations between $1-20 \mathrm{ng} \cdot \mathrm{g}^{-1}$ with some sporadic high values up to $600 \mathrm{ng} \cdot \mathrm{g}^{-1}$ in narrow layers. The chemical fingerprint points to biomass burning causing the high ammonium peaks.
\end{abstract}

\section{Sampling and measurements}

A continuous $\mathrm{NH}_{4}^{+}$profile was obtained by using a continuous melting technique [Stauffer et al., 1988] combined with a fluorescence detector [Genfa and Dasgupta, 1989] providing a spatial resolution of about $1 \mathrm{~cm}$. The continuous bigh resolution ammonium measurements, performed immediatly after core recovery allowed us to choose specific core sections for comprehensive chemical studies. Inorganic $\left(\mathrm{Na}^{+}, \mathrm{NH}_{4}^{+}, \mathrm{K}^{+}, \mathrm{Ca}^{++}, \mathrm{Mg}^{+}, \mathrm{F}, \mathrm{Cl}^{-}, \mathrm{NO}_{3}^{-}\right.$and $\left.\mathrm{SO}_{4}^{-}\right)$and organic (formate : $\mathrm{HCOO}$, acetate : $\mathrm{CH}_{3} \mathrm{COO}$, methanesulfonate : $\mathrm{CH}_{3} \mathrm{SO}_{3}^{-}$and oxalate : $\mathrm{C}_{2} \mathrm{O}_{4}^{-}$) ions were measured directly in the field by ion chromatography (Dionex 4500) on discrete samples of $5 \mathrm{~cm}$ length. Anion determination was performed using an AS5 separator column and a gradient pump system [Legrand et al., in press]. Extended investigations of organic ions to separate glycolate $\left(\mathrm{C}_{2} \mathrm{H}_{3} \mathrm{O}_{3}^{-}\right)$have been performed using an Omnipax 500 separator column. Cation measurements were performed using analytical methods and working conditions described elsewhere [Saigne et al., 1987]. Each ice sample was cleaned mechanically in the field immediately after drilling and was stored before the measurement in airtight glass bottles in order to minimize possible contamination.

Copyright 1992 by the American Geophysical Union.

Paper number 91GL03121

094-8534/92/91GL-03132\$03.00

\section{Results and discussion}

The $500 \mathrm{~m}$ long continuous $\mathrm{NH}_{4}^{+}$profile contains more than 100 peaks showing concentrations higher than $100 \mathrm{ng} \cdot \mathrm{g}^{-1}$ in contrast to the background range of 1 to $20 \mathrm{ng} \cdot \mathrm{g}^{-1}$. Detailed analyses were performed on 10 ice core sections containing events exhibiting $\mathrm{NH}_{4}{ }^{+}$levels higher than 100 $\mathrm{ng} \cdot \mathrm{g}^{-1}$. The selected sections cover the whole range of $\mathrm{NH}_{4}^{+}$ concentrations including two of the 5 highest. Two examples are shown in Figure 1. The continuous analysis and the discrete measurements of $\mathrm{NH}_{4}{ }^{+}$are in good agreement taking into account the different spatial resolution of the two sets of measurements. Figure 1 shows that the $\mathrm{NH}_{4}{ }^{+}$spikes coincide with clearly elevated levels of formate, acetate, oxalate and glycolate. Such coincident increases in the levels of organic species with levels of $\mathrm{NH}_{4}{ }^{+}$are also found in all 10 ice core sections that were examined (these results are not reported here). The $\mathrm{NH}_{4}^{+}$spikes coincide with lows in sodium concentration in all examined ice core sections which indicates that the $\mathrm{NH}_{4}^{+}$events occured during summer precipitation since $\mathrm{Na}$ levels are a minimum in summer [Mayewski et al., 1987].

Figure 2 shows the $\mathrm{NH}_{4}^{+}$and $\mathrm{HCOO}^{-}$concentration of all measured samples along the 10 studied ice core sections. For $\mathrm{NH}_{4}{ }^{+}$levels higher than $20 \mathrm{ng} \cdot \mathrm{g}^{-1}$, an enhancement of formate above its background level (7 to 15 ng. $\mathrm{g}^{-1}$ ) with a $\mathrm{NH}_{4}{ }^{+} / \mathrm{HCOO}$ molar ratio close to one was observed. The others organic ions are also clearly enhanced but their contribution to the ionic budget remains small as shown Figure 1.

Unlike with $\mathrm{NH}_{4}^{+}$, a continuous highly resolved record of organic acids and sodium are not available due to analytical limitations. Nevertheless, all the $\mathrm{NH}_{4}^{+}$peaks that we have analysed are accompanied by an increase of organic acid level and occur in summer.

The recorded ammonium peaks are very sharp, the width of the peak is given by the limitation of the spatial resolution of the continuous measuring system. For the Summit core the resolution of $1 \mathrm{~cm}$ corresponds roughly to $10 \%$ of the yearly accumulation. The perturbation in the ammonium and organic acid content is therefore limited to a single or a few consecutive precipitation events and the time between them. Because both the concentration and the chemical compositions are heavily disturbed, these changes have to be associated with corresponding changes of the atmospheric composition over Greenland.

Ammonium will be emitted originally as $\mathrm{NH}_{3}$, whereas the organic acids are emitted directly and are also produced in 
the atmosphere by oxidation of hydrocarbons. The ammonium peaks in the Summit core must be caused by a source which emits ammonia, organic acids and or hydrocarbons on a time scale of days to a month. Additionally, the emissions must occur in such a way, that they have the possibility to reach Greenland, therefore low level and low intensity sources such as excrements from wild animals or emissions from soils can be ruled out. Only biomass burning, and more specifically large forest fires, satisfy the above mentionned conditions. Plumes from forest fires have enough energy, that they can extend to the free troposphere where they can be efficiently transported over large distances.

Estimates of the contribution of $\mathrm{NH}_{3}$ from biomass burning to the total natural emissions ranges from $10 \%$ to $80 \%$ [Hegg et al., 1988 ; Wameck, 1988 ; Bottger et al., 1981] . During the time of an active forest fire, it is very likely that these $\mathrm{NH}_{3}$ emissions clearly dominate all other sources. It is therefore our hypothesis, that the observed ammonium peaks in the Summit ice are caused by biomass buming. Indeed, the chemical composition of biomass burning plumes shows

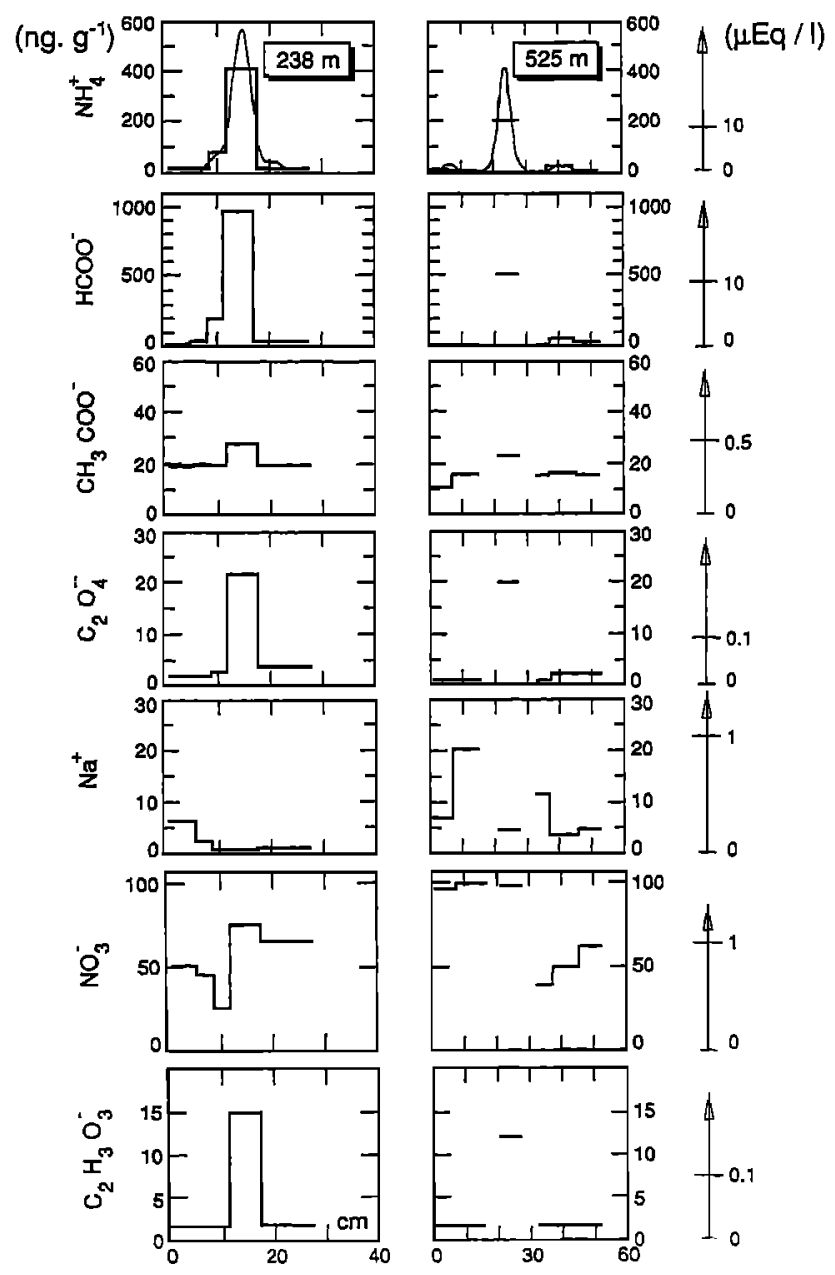

Fig. 1 : Chemical perturbations observed along two $\mathrm{NH}_{4}^{+}$ events recorded by FIA measurements (continuous line) at 238 and $525 \mathrm{~m}$ depth corresponding to 930 and 2200 years $\mathrm{BP}$ respectively at Summit. strong enhancement of the level of $\mathrm{NH}_{4}^{+}$and of various organic species including organic acids [Andreae et al, 1988]. In particular, the presence of dicarboxylate as oxalate in the remote atmosphere is strong evidence of a combustion process at the source [Baudet et al., 1990].

Intensive studies of such plumes were carried out in the Amazon basin [Jacob et al., in press] and in the North American part of the Arctic during the NASA GTE ABLE $2 \mathrm{~A}$ project [Talbot et al., in press]. These measurements showed not only an enhancement of formic acid and ammonium but also of acetic acid and nitric acid or nitrate respectively. There are clear deviations in the chemical composition of snow layers exhibiting ammonium peaks compared to the chemical fingerprint of plumes of high latitudes forest fires [Talbot et al., in press]. Formate is 10 to 100 times more abundant than acetate and nitrate shows no enhancement in the ice (Figure 1). Changes in the chemical signature of the emitted mixture of biomass buming will occur during the transport, during the scavenging processes and eventually after deposition at the snow surface. During long range transport larger amounts of formic than acetic acid are produced during the oxidation of various hydrocarbons [Jacob and Wofsy, 1988], shifting the ratio systematically toward formic acid. Post depositional redistribution and losses of volatile organic compounds such as HCHO have been reported [Staffelbach et al., 1991]. Losses of acetate have also been observed in the subsurface snow layers at Summit and it is likely that the preservation of acetate in the snow is not as good as for formate.

The vapor pressure of ammonium formate is much higher than the vapor pressure of ammonium nitrate. It is therefore possible that nitrate is washed out effectively because it stays in the aerosol form, whereas ammonia and formic acid can survive in the gas phase during the transport of the air masses to Greenland. For present day conditions, the large amount of anthropogenic emitted $\mathrm{SO}_{2}$ causes a rapid conversion into the stable ammonium sulfate which might prevent that ammonia emitted from forest fires from reaching

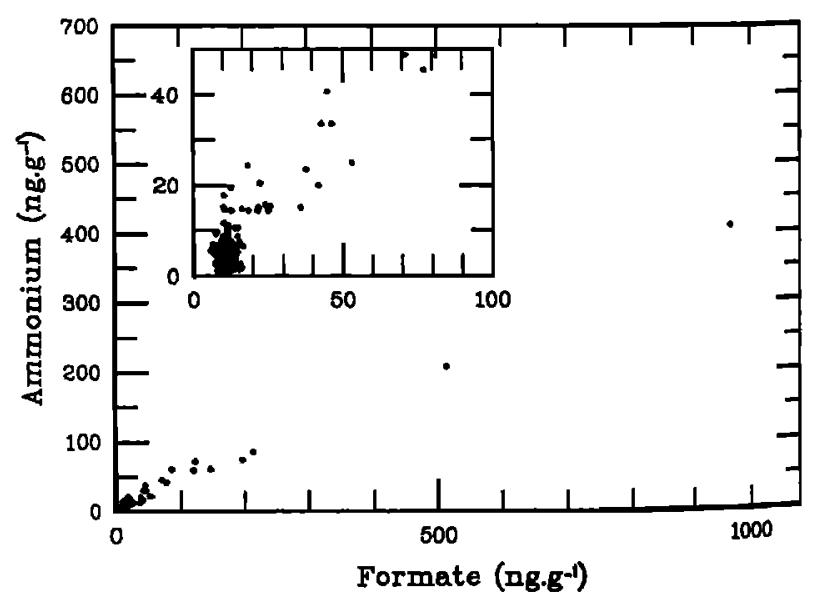

Fig. $2: \mathrm{NH}_{4}{ }^{+}$and $\mathrm{HCOO}$ content observed along ten ice core sections which exhibit ammonium peaks. For ammonium content exceeding $20 \mathrm{ng} . \mathrm{g}-1$, the calculated slope of the regression line $(0.43)$ is close to the $\mathrm{NH}_{4}^{+} / \mathrm{HCOO}^{-}$molar ratio $(0.40)$. 
the Greenland ice cap in form of ammonium formate. It is therefore likely that larger forest fires which occured in the last decades will not leave their traces in the snow of Greenland.

Finally the question has to be addressed whether forest fires have the potential to cause the observed perturbation in the ammonium concentration in the Greenland ice. The NASA GTE ABLE 3A project [Talbot et al., in press] revealed enhancements of $\mathrm{NH}_{4}^{+}$in a 1-2 days old plumes by a factor of 6 compared to the measured present day background concentration in the Northern American Arctic and by a factor of 10 compared to concentrations measured at the atmospheric camp (ATM) in Summit in the summers of 1989 and 1990. These factors are of the same order of magnitude as the ratio of the $\mathrm{NH}_{4}^{+}$peaks to the summer background values in the ice.

The ammonium peaks at 238 meters below surface e.g. corresponds to $\mathrm{aHH}_{4}^{+}$deposition of approximately $18 \times 10^{-6}$ $\mathrm{kg} / \mathrm{m}^{2}$, assuming a peak concentration of $600 \mathrm{ng} \cdot \mathrm{g}^{-1}$ and a half width of $3 \mathrm{~cm}$ water equivalent. An area of roughly $15,000 \times 400 \mathrm{~km}^{2}$ would be covered, if it is assumed that the plume of a forest fire at $70^{\circ} \mathrm{N}$ spreads around the globe with a width of $400 \mathrm{~km}$. Assuming further a uniform deposition in this band, a total emission of approximately $10^{8} \mathrm{~kg} \mathrm{NH}_{3}$ is required. This is a few percent of the estimated $3 \times 10^{9} \mathrm{~kg}$ $\mathrm{NH}_{3}$ emissions from forest fires in the northern hemisphere [Hegg et al., 1988], which is not an unrealistically high percentage.

\section{Conclusion}

The comprehensive study of ammonium perturbations observed in Greenland snow layers have shown that such summer events are characterized by a large increase of several organic species and by an absence of nitrate changes. This study of the Greenland precipitation suggests that the composition of the atmosphere in high northern latitudes have been sporadically disturbed by strong inputs originating from high latitude forest fires. Such perturbations by one or two orders of magnitude in the atmospheric content of reactive species may have strongly disturbed the photochemistry of these high latitudes regions. This study also points out the possibility of reconstructing past biomass burning events in the northern high latitudes which could have been modulated by past climatic conditions.

Acknowledgements. The deep ice core at Summit was obtained by the Greenland Ice Core Project (GRIP) an ESF associate programme, with Belgium, Denmark, France, Germany, Great Britain, Iceland, Italy and Switzerland participating. The laboratory work was supported by the CNRS (ATP "Cycles Biogéochimiques") and through COST 611. We thank Katrin Fuhrer and Markus Möll for their great effort to provide the continuous $\mathrm{NH}_{4}^{+}$profile in the field.

\section{References}

Andreae, M.O., R.W. Talbot, T.W. Andreae, and R.C. Harriss, Formic and acetic acid over the central amazon Region, Brazil 1. dry season, J. Geophys. Res. 93, 1616-1624, 1988.

Andreae, M.O. and thirteen others, Biomass burning emissions and associated haze layers over Amazonia, I. Geophys. Res., 93, 1509-1527, 1988.

Baudet, J.G.R., J.P. Lacaux, J.J. Bertrand, F. Desalmand, J. Servant, and V. Yoboue, Presence of an atmospheric oxalate source in the intertropical zone, its potential action in the atmosphere, Atmos. Res. 25, 465477, 1990.

Bottger, A., G. Gravenhorst, and D.H. Ehhalt, in Atmospheric Aerosols and Nuclei, edited by A.F. Roddy and J.C. O'Connor, pp, 287-293, Galway University Press, Galway, Ireland, 1981.

Genfa, Z., and P.K. Dasgupta, Fluorometric measurements of aqueous ammonium ion in a flow injection system, Anal. Chem. 61, 408-412, 1989.

Hegg, D.A., L.F. Radke, P.V. Hobbs, and P.J. Riggan, Ammonia emissions from biomass burning, Geophys. Res. Lett. 15, 335-337, 1988.

Jacob, D. and S.C. Wofsy, Photochemistry of biogenic emissions over the Amazon forest, J. Geophys. Res. 93, 1477-1486, 1988.

Jacob, D. and thirteen others, J. Geophys. Res. in press. (Special issue on GTE ABLE 3A)

Legrand, M., C. Feniet-Saigne, E.S. Saltzman, and C. Germain, Spatial and temporal variations of methanesulfonic acid and non sea salt sulfate in antarctic ice, J. Atmos. Chem. in press.

Mayewski, P.A., M.J. Spencer, W.B. Lyons, and M.S. Twickler, Seasonal and spatial trends in South Greenland snow chemistry, Atmos. Environ. 21, 863-869, 1987.

Saigne, C., S. Kirchner, and M. Legrand, Ion chromatographic measurements of ammonium, fluoride, acetate, formate and methanesulfonate at very low levels in antarctic ice, Anal. Chim. Acta, 203, 11-21, 1987.

Staffelbach, T., A. Neftel, B. Stauffer, and D. Jacob, A record of the atmospheric methane sink from formaldehyde in polar ice core, Nature, 349, 603-605, 1991.

Stauffer, B., J. Burkhalter, and A. Sigg, New methods in ice core processing, 151-157, in proceedings of the third international workshop on ice drilling technology, Grenoble, 10-14 octobre 1988, eds. C. Rado and D. Beaudoing, 1988.

Talbot, R.W., A.S. Vijgen, and R.C. Harriss, J. Geophys. Res., in press. (Special issue on GTE ABLE 3A).

Wameck, P., Chemistry of the natural atmosphere, Academic press. Inc., San Diego, California, 1988.

M. Legrand and M. De Angelis, Laboratoire de Glaciologie et Geophysique de l'Environnement, B.P. 96, 38402 St Martin d'Hères cedex, France

T. Staffelbach, A. Neftel and B. Stauffer, Physical Institut, University of Bem, CH-3012 Berne, Switzerland

(Received October 30, 1991 ; accepted December 17, 1991.) 